Supplementary Materials for

\title{
Conversion of Methane with Oxygen to Produce Hydrogen Catalyzed by Triatomic $\mathrm{Rh}_{3}{ }^{-}$Cluster Anion
}

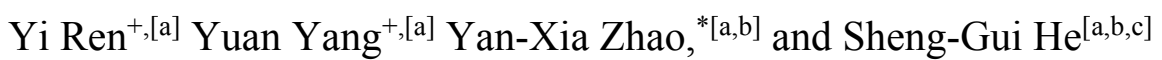

[a] State Key Laboratory for Structural Chemistry of Unstable and Stable Species, Institute of Chemistry, Chinese Academy of Sciences, Beijing 100190 (P. R. China)

[b] Beijing National Laboratory for Molecular Sciences and CAS Research/Education Centre of Excellence in Molecular Sciences, Beijing 100190 (P. R. China)

[c] University of Chinese Academy of Sciences, Beijing 100049 (P. R. China)

*Corresponding author, E-mail: chemzyx@iccas.ac.cn (Y.-X. Z.) phone: +86-10-62423763; fax: $+86-10-62559373$. 


\section{Contents}

1. Method. (Pages S3 and S4)

\section{Additional experimental results for cluster reactions.}

Figure S1. Mass spectra for the reactions of $\mathrm{Rh}_{3} \mathrm{O}_{y}{ }^{-}\left(y=0\right.$ or 1) with $\mathrm{CH}_{4}, \mathrm{CD}_{4},{ }^{16} \mathrm{O}_{2}$ or $\mathrm{H}_{2}$. (Page S5)

Figure S2. Kinetic analysis for the reactions of $\mathrm{Rh}_{3} \mathrm{O}_{y}{ }^{-}(y=0$ or 1$)$ with $\mathrm{CH}_{4}, \mathrm{CD}_{4}, \mathrm{O}_{2}, \mathrm{CO}$ or $\mathrm{H}_{2}$. (Page S6)

3. Additional theoretical results for structures of reaction intermediates and reaction pathways.

Figure S3. Structural assignment of reaction intermediate $\mathrm{Rh}_{3} \mathrm{CH}_{2}{ }^{-}$. (Page S7)

Figure S4. Structural assignment of reaction intermediate $\mathrm{Rh}_{3} \mathrm{O}^{-}$. (Page S8)

Figure S5. Potential energy profile for the reaction of ${ }^{5} \mathrm{Rh}_{3}{ }^{-}+\mathrm{CH}_{4}(\mathrm{R} 1) \rightarrow{ }^{3} \mathrm{Rh}_{3} \mathrm{CH}_{2}{ }^{-}+\mathrm{H}_{2}(\mathrm{P} 1)$. (Page S9)

Figure S6. Potential energy curves (PECs) for interconversion of ${ }^{5} \mathrm{I} 4 \rightarrow{ }^{3} \mathrm{TS} 4$ in the reaction of ${ }^{5} \mathrm{Rh}_{3}{ }^{-}$ with $\mathrm{CH}_{4}$. (Page S10)

Figure S7. Potential energy profile for the reactions of ${ }^{3} \mathrm{Rh}_{3} \mathrm{CH}_{2}{ }^{-}+\mathrm{O}_{2}(\mathrm{R} 2) \rightarrow{ }^{3} \mathrm{Rh}_{3} \mathrm{O}^{-}+\mathrm{H}_{2}+\mathrm{CO}(\mathrm{P} 2)$ and ${ }^{3} \mathrm{Rh}_{3} \mathrm{CH}_{2}{ }^{-}+\mathrm{O}_{2} \rightarrow{ }^{5} \mathrm{Rh}_{3}{ }^{-}+\mathrm{H}_{2}+\mathrm{CO}_{2}(\mathrm{P} 3)$. (Page S11)

Figure S8. Potential energy curves (PECs) for interconversion of ${ }^{3} \mathrm{TS} 19 \rightarrow{ }^{5} \mathrm{I} 22$ for generation of ${ }^{5} \mathrm{Rh}_{3}{ }^{-}$ $+\mathrm{CO}_{2}$ from $\mathrm{Rh}_{3} \mathrm{CO}_{2}{ }^{-}$. (Page $\mathrm{S} 12$ )

Figure S9. Potential energy profile for the reaction of ${ }^{3} \mathrm{Rh}_{3} \mathrm{CH}_{2}{ }^{-}+\mathrm{O}_{2}(\mathrm{R} 2) \rightarrow{ }^{3} \mathrm{Rh}_{3} \mathrm{O}^{-}+\mathrm{CH}_{2} \mathrm{O}$. (Page S13)

Table S1. Virtual frequency values of all of the transition states. (Page S14)

4. References (Page S15) 


\section{Method.}

Experimental Method. The negatively charged rhodium clusters $\left(\mathrm{Rh}_{x}^{-}\right)$were generated by laser ablation of a rotating and translating $\mathrm{Rh}$ disk in the presence of a 6 atm He carrier gas. The reactivity experiments were carried out in a double ion trap system, which includes two quadrupole mass filters (QMF) and two linear ion traps (LIT). Among many generated $\mathrm{Rh}_{x}{ }^{-}$clusters, the triatomic $\mathrm{Rh}_{3}{ }^{-}$ions of interest were mass-selected by using the first $\mathrm{QMF}^{1}$ and entered into the first LIT reactor, ${ }^{2}$ where they were confined and thermalized by collisions with a pulse of buffer gas He and then reacted with ${ }^{12} \mathrm{CH}_{4}$ or $\mathrm{CD}_{4}$. The second QMF mass-selected the product ions (e.g., $\left.\mathrm{Rh}_{3} \mathrm{CH}_{2}{ }^{-}\right)$resulting from the first LIT to inject into the second LIT for further reaction with ${ }^{16} \mathrm{O}_{2}$ or ${ }^{18} \mathrm{O}_{2}$ molecule. The $\mathrm{Rh}_{3} \mathrm{O}^{-}$cluster was also generated by laser ablation of $\mathrm{Rh}$ disk in the presence of $0.02 \%{ }^{16} \mathrm{O}_{2} / \mathrm{He}$ for reaction with reductant molecules of $\mathrm{CO}$ and $\mathrm{H}_{2}$. The prepared $\mathrm{Rh}_{3} \mathrm{O}^{-}$anions were mass-selected by a QMF, thermalized by collisions with buffer gas $\mathrm{He}$, and then interacted with $\mathrm{CO}$ or $\mathrm{H}_{2}$ in a LIT. A reflection time-of-flight mass spectrometer ${ }^{3}$ (TOF-MS) was used to detect the cluster ions ejected from the LIT reactor.

The rate constants of the reactions between cluster ions and small molecules (e.g., $\mathrm{CH}_{4}, \mathrm{O}_{2}, \mathrm{CO}$ or $\mathrm{H}_{2}$ ) were determined by using the following equations:

$$
\begin{aligned}
& I_{\mathrm{R}}=\exp \left(-k_{1} \times \rho \times t_{\mathrm{R}}\right) \\
& I_{\mathrm{P}}=1-\exp \left(k_{1} \times \rho \times t_{\mathrm{R}}\right)
\end{aligned}
$$

in which $I_{\mathrm{R}}$ and $I_{\mathrm{p}}$ are the relative intensities of the reactant and product cluster ions, respectively; $k_{1}$ is the pseudo-first-order rate coefficient, $\rho$ is the molecular density of small molecules in the ion trap reactor, and $t_{\mathrm{R}}$ is the reaction time.

The photoelectron imaging spectroscopy (PEIS) experiments of reaction intermediates $\mathrm{Rh}_{3} \mathrm{CH}_{2}{ }^{-}$ and $\mathrm{Rh}_{3} \mathrm{O}^{-}$were conducted with a separate apparatus of tandem TOF-MS equipped with a laser ablation cluster source, a LIT reactor, and a photoelectron imaging spectrometer. The $\mathrm{Rh}_{3} \mathrm{CH}_{2}{ }^{-}$was generated from the reaction of pre-formed $\mathrm{Rh}_{3}{ }^{-}$cluster with $\mathrm{CH}_{4}$ in the LIT reactor, whereas $\mathrm{Rh}_{3} \mathrm{O}^{-}$ was produced by laser ablation of $\mathrm{Rh}$ disk in the presence of $1 \%{ }^{16} \mathrm{O}_{2} / \mathrm{He}$ in the cluster source. The generated ions were selected by a mass gate and crossed with a $500 \mathrm{~nm}$ laser beam. The electrons from photo-detachment were energy-analyzed by the photoelectron imaging spectrometer. ${ }^{4}$ The PEIS spectrum was calibrated using the spectrum of $\mathrm{Au}^{-}$taken at the similar conditions. The resolution of the photoelectron imaging spectrometer was approximately $30 \mathrm{meV}$ at electron kinetic energy of $1 \mathrm{eV}$.

Theoretical Method. The density functional theory (DFT) calculations using Gaussian 09 program ${ }^{5}$ were carried out to investigate the structures of reaction intermediates $\mathrm{Rh}_{3} \mathrm{X}^{-}\left(\mathrm{X}=\mathrm{CH}_{2}, \mathrm{CO}, \mathrm{O}\right)$ as well as the reaction pathways of $\mathrm{Rh}_{3}{ }^{-}+\mathrm{CH}_{4}, \mathrm{Rh}_{3} \mathrm{CH}_{2}{ }^{-}+\mathrm{O}_{2}$, and $\mathrm{Rh}_{3} \mathrm{O}^{-}+\mathrm{CO}$. The PBE functional ${ }^{6}$ has been proved to perform well for bare rhodium clusters ${ }^{7}$ so the results by PBE method are given throughout this work. The TZVP basis sets ${ }^{8}$ for $\mathrm{C}, \mathrm{H}$ and $\mathrm{O}$ atoms and the D95V basis set combined with the Stuttgart/Dresden relativistic effective core potentials (denoted as SDD in Gaussian software $)^{9}$ for Rh atom were used. The reaction pathway calculations involved geometry optimization of reaction intermediates (IMs) and transition states (TSs) through which the IMs transfer to each other. The initial guess structures of the TS species were obtained through relaxed potential energy surface scans using single or multiple internal coordinates. ${ }^{10}$ Vibrational frequency calculations were performed to check that the IMs or TSs have zero and only one imaginary frequency, respectively. Intrinsic reaction coordinate calculations were performed so that a transition state connects two 
appropriate local minima. The zero-point vibration corrected energies $\left(\Delta H_{0}\right)$ in unit of eV are reported in this work.

The Rice-Ramsperger-Kassel-Marcus (RRKM) theory ${ }^{11}$ and RRKM-based variational transition state theory (VTST) ${ }^{11}$ were used to calculate (i) the rate $\left(k_{\mathrm{d}}\right)$ for desorption of neutral product (e.g., CO) from the reaction intermediate $\left.\mathrm{Rh}_{3} \mathrm{CO}_{2}{ }^{-}{ }^{3} \mathrm{I} 19\right)$ and (ii) the rate $\left(k_{\mathrm{IC}}\right)$ for internal conversion of $\mathrm{Rh}_{3} \mathrm{CO}_{2}^{-}\left({ }^{3} \mathrm{I} 19\right)$ in the reaction pathway of ${ }^{3} \mathrm{Rh}_{3} \mathrm{CH}_{2}{ }^{-}+\mathrm{O}_{2}$. For these calculations, the energy $(E)$ of the reaction intermediate and the energy barrier $\left(E^{t}\right)$ for each step were needed. The reaction intermediate $\left.\mathrm{Rh}_{3} \mathrm{CO}_{2}{ }^{-}{ }^{3}{ }^{3} 19\right)$ possesses the vibrational energies $\left(E_{\mathrm{vib}}\right)$ of $\mathrm{Rh}_{3} \mathrm{CH}_{2}{ }^{-}$and $\mathrm{O}_{2}$, the center of mass kinetic energy $\left(E_{\mathrm{k}}\right)$, and the binding energy $\left(E_{\mathrm{b}}\right)$ between the separated reactants according to the distribution of degree of freedom. The $k$ value was calculated by the Equation S2:

$$
k(E)=g N^{\ddagger}\left(E-E^{\ddagger}\right) / \rho(E) / h
$$

in which $g$ is the symmetry factor ( $g$ is taken as 1$), \rho(E)$ denotes the density of states of the reaction intermediates at the energy $E, N^{\neq}\left(E-E^{\ddagger}\right)$ is the total number of the states of the transition state with a barrier $E^{f}$ ( $E^{\neq}$was zero-point-vibration corrected energy), and $h$ is the Planck constant. The $\rho(E)$ and $N^{\ddagger}\left(E-E^{\ddagger}\right)$ were obtained by the direct count method ${ }^{12}$ with the DFT-calculated vibrational frequencies under the approximation of harmonic vibrations. The $E_{\mathrm{vib}}, E_{\mathrm{b}}$, and $E^{\neq}$were all from DFT calculations and $E_{\mathrm{k}}=\mu v^{2} / 2$, in which $\mu$ is the reduced mass and $v$ is the velocity. Because no distinct transition state exists on the potential energy surfaces for desorption of $\mathrm{CO}$ from $\mathrm{Rh}_{3} \mathrm{CO}_{2}{ }^{-}\left({ }^{3} \mathrm{I} 19\right)$, the VTST calculations were performed through partial geometry optimizations of $\mathrm{Rh}_{3} \mathrm{CO}_{2}{ }^{-}\left({ }^{3} \mathrm{I} 19\right)$ by fixing the distance between $\mathrm{Rh}$ atom and $\mathrm{C}$ atom at variable values. The $k(E)$ value of each step was estimated and the minimum rate was considered as the $k_{\mathrm{d}}$ value. 
2. Additional experimental results for cluster reactions.
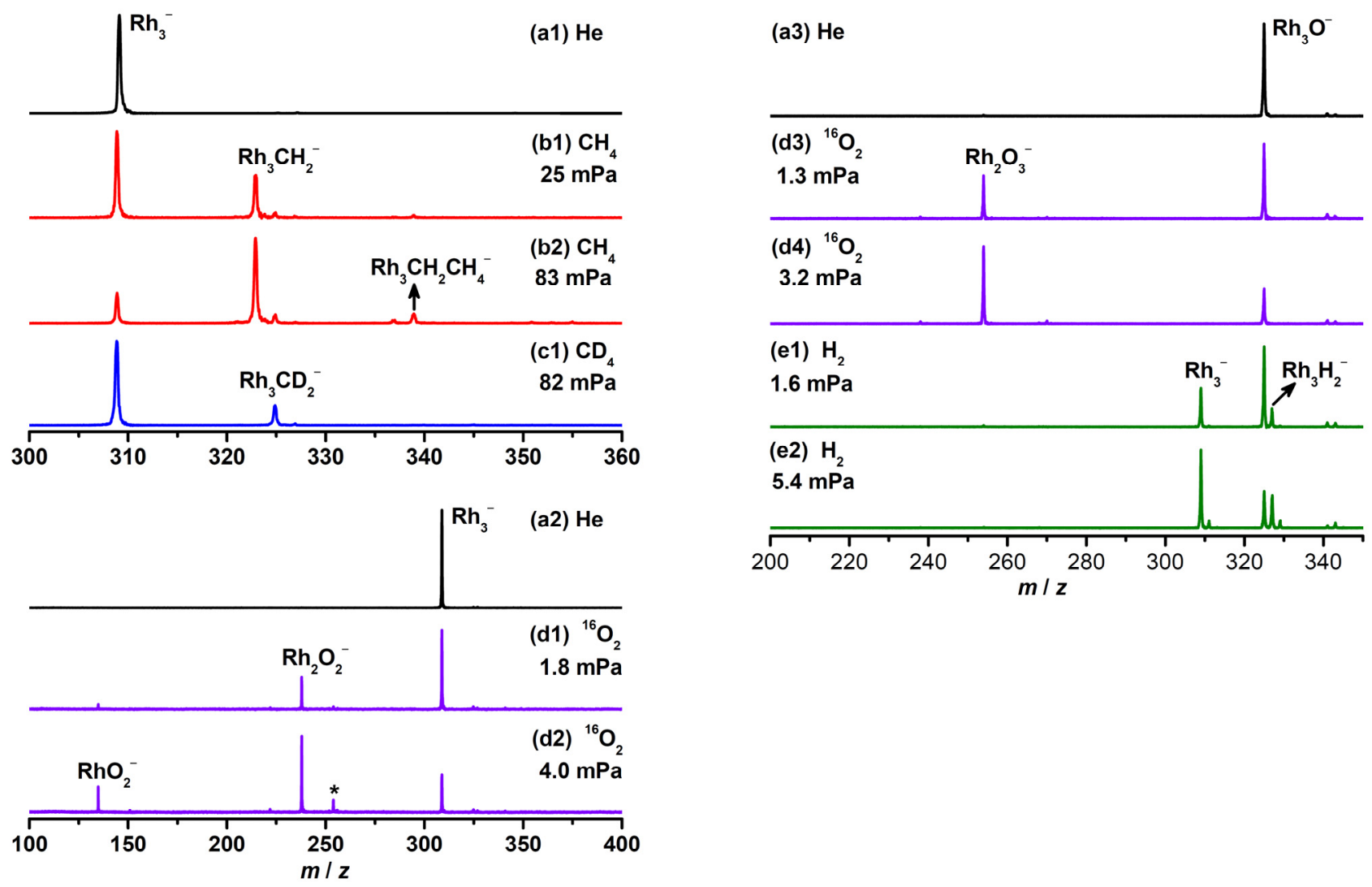

Figure S1. TOF mass spectra for the reactions of mass-selected $\mathrm{Rh}_{3} \mathrm{O}_{y}{ }^{-}\left(y=0\right.$ or 1 ) with $\mathrm{He}(\mathrm{a}), \mathrm{CH}_{4}$ (b), $\mathrm{CD}_{4}(\mathrm{c}),{ }^{16} \mathrm{O}_{2}$ (d) or $\mathrm{H}_{2}$ (e) at room temperature. The pressures of reactant gases are shown. The reaction times are $3.6 \mathrm{~ms}$ for (b and c), $3.3 \mathrm{~ms}$ for (d1and d2), $3.6 \mathrm{~ms}$ for ( $\mathrm{d} 3$ and d4), $2.2 \mathrm{~ms}$ for (e), respectively. The peak marked with an asterisk in pannel (d2) can be assigned to $\mathrm{Rh}_{2} \mathrm{O}_{3}{ }^{-}$originating from the oxidation of $\mathrm{Rh}_{3} \mathrm{O}^{-}$that was generated from the reaction of $\mathrm{Rh}_{3}{ }^{-}$with residual water in the gas handling system. 

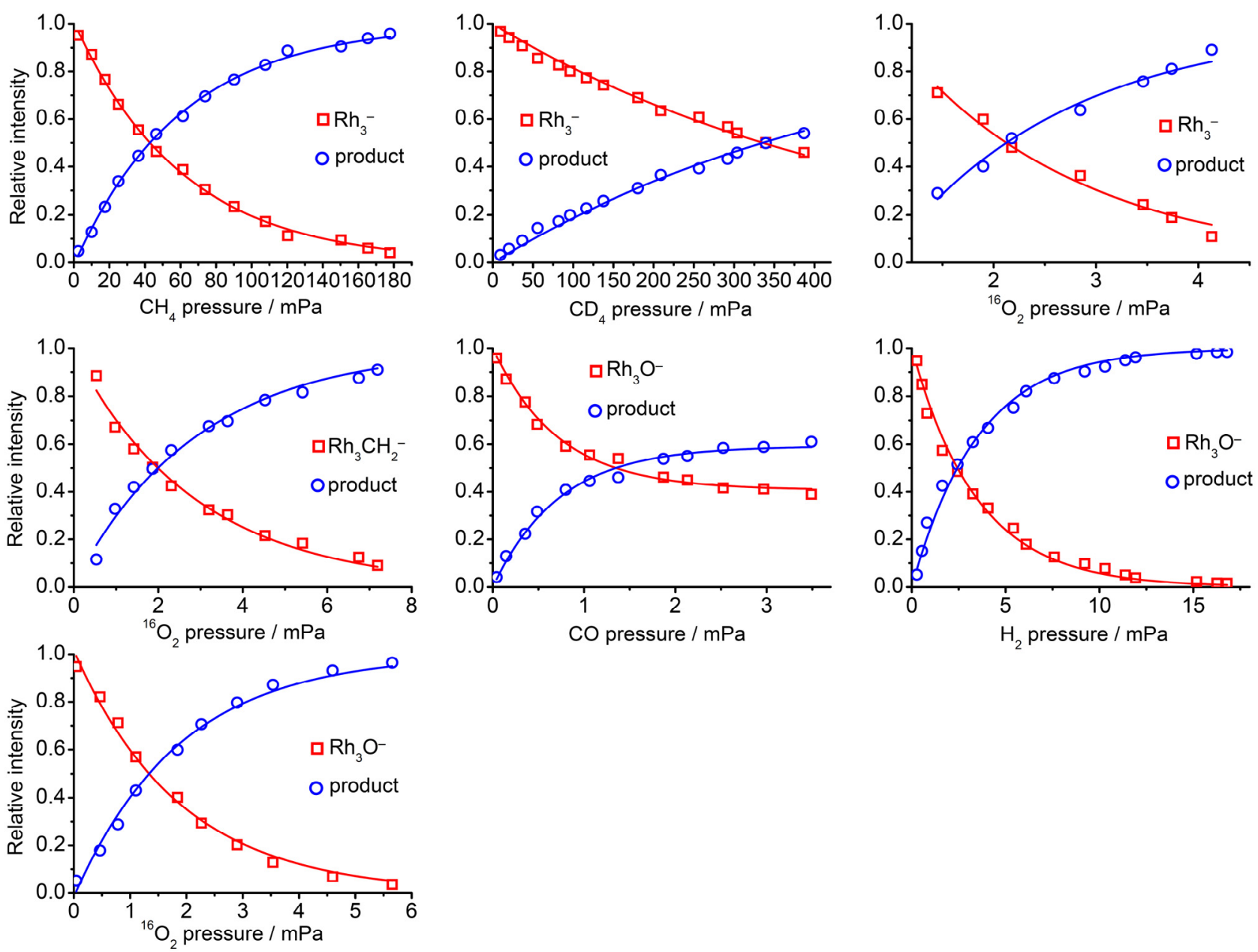

Figure S2. Variations of relative ion intensities with respect to the $\mathrm{CH}_{4}, \mathrm{CD}_{4},{ }^{16} \mathrm{O}_{2}, \mathrm{CO}$ or $\mathrm{H}_{2}$ pressures in the reaction of $\mathrm{Rh}_{3} \mathrm{O}_{y}{ }^{-}(y=0$ or 1$)$ cluster with $\mathrm{CH}_{4}, \mathrm{CD}_{4},{ }^{16} \mathrm{O}_{2}, \mathrm{CO}$ or $\mathrm{H}_{2}$. The solid lines are fitted to the experimental data points by using the equations derived with the approximation of the pseudofirst-order reaction mechanism for the reactive species. 


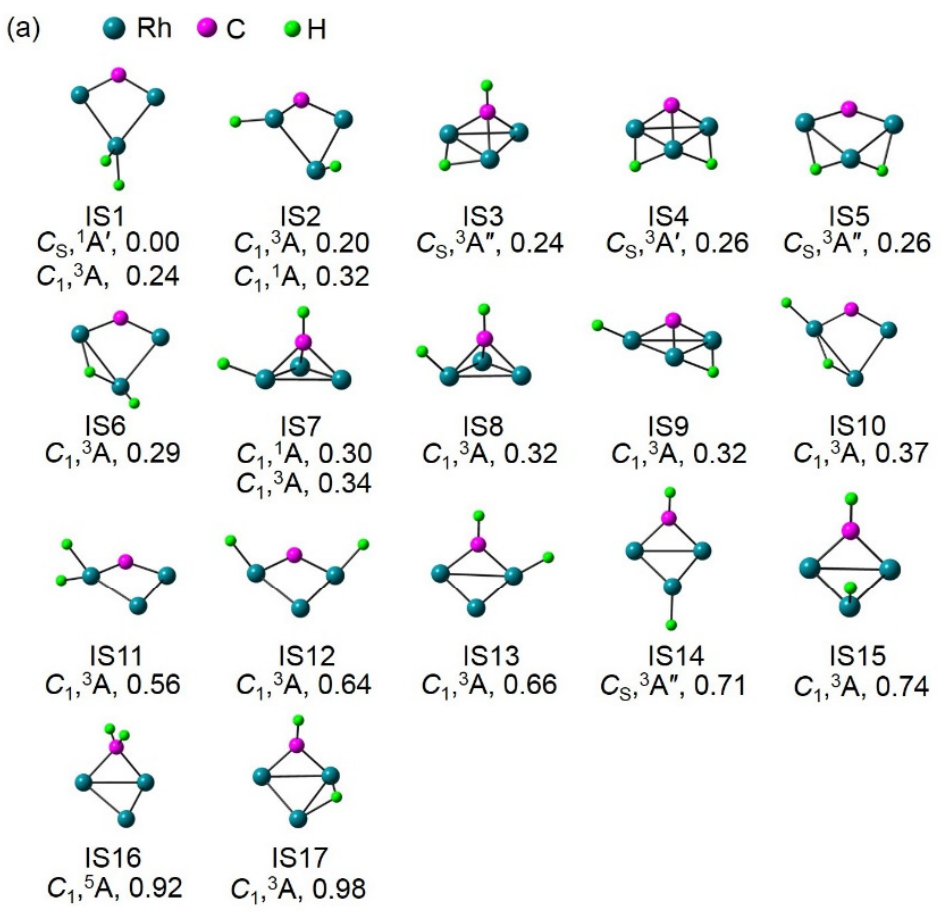

(b)

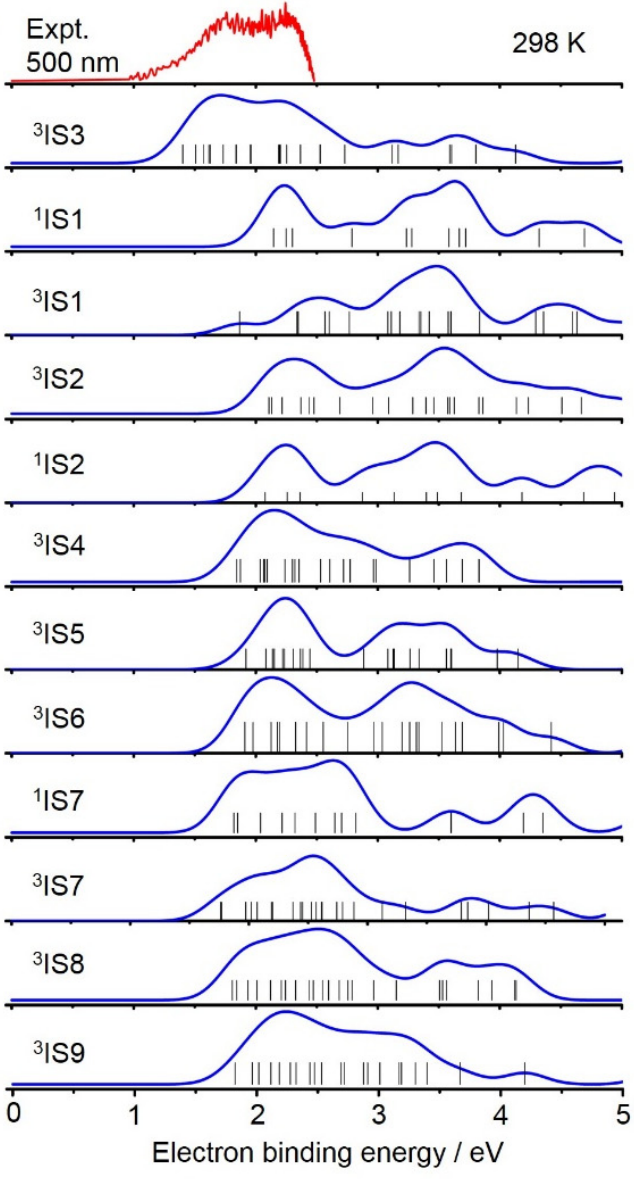

Figure S3. (a) DFT calculated isomeric structures of reaction intermediate $\mathrm{Rh}_{3} \mathrm{CH}_{2}{ }^{-}$. The relative energies are given in $\mathrm{eV}$. The symmetry and electronic states are also shown. (b) Comparison between the experimental photoelectron spectrum and the simulated density of states (DOS) spectra for the low-lying energy isomers of $\mathrm{Rh}_{3} \mathrm{CH}_{2}{ }^{-}$with different electronic states. The DOS spectra were conducted by fitting the distribution of the transition lines with unit-area Gaussian functions of 0.40 $\mathrm{eV}$ full width at half maximum (FWHM). 
(a)
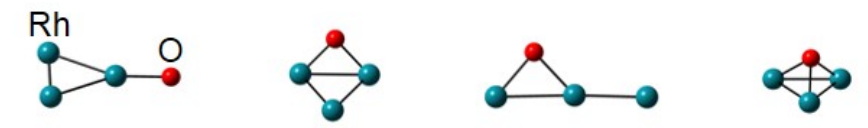

IS18

IS19

IS 20

IS 21

$\mathrm{C}_{2 \mathrm{~V}},{ }^{5} \mathrm{~B}_{1}, 0.00$

$C_{S},{ }^{3} A^{\prime \prime}, 0.12$

$C_{\mathrm{S}},{ }^{5} \mathrm{~A}^{\prime}, 0.21$

$\mathrm{C}_{\mathrm{S}},{ }^{3} \mathrm{~A}^{\prime \prime}, 0.41$

$\mathrm{C}_{1},{ }^{5} \mathrm{~A}, 0.73$

$C_{S},{ }^{5} \mathrm{~A} ", 0.79$

(b)
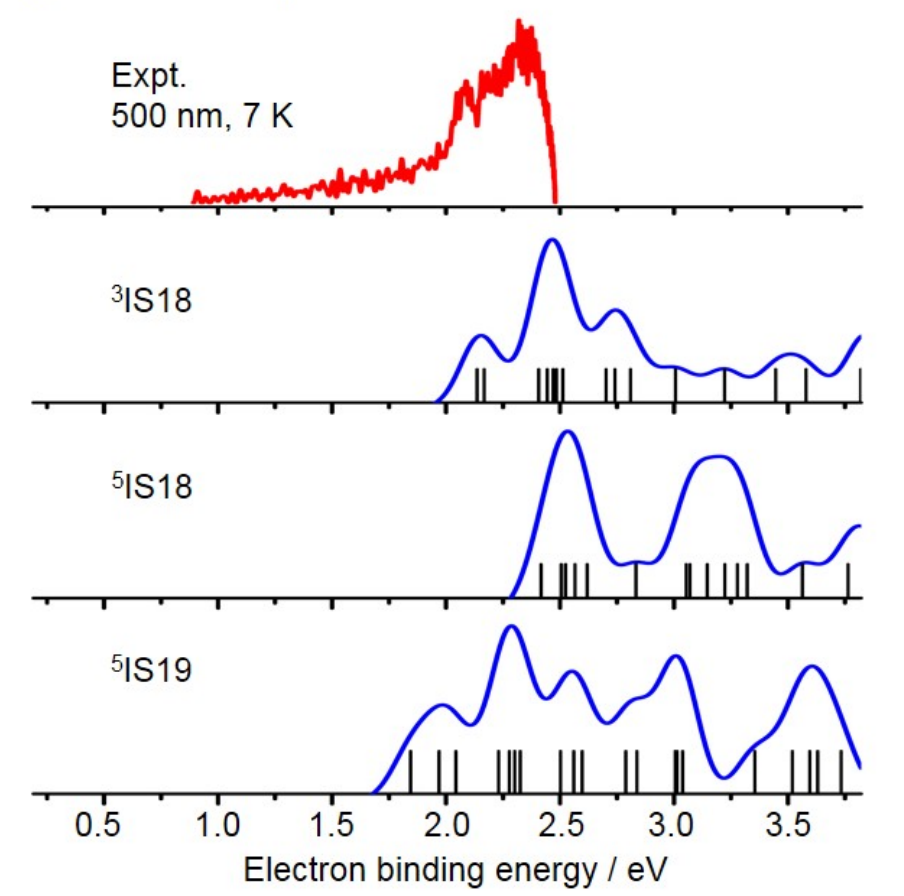

Figure S4. (a) DFT calculated isomeric structures of reaction intermediate $\mathrm{Rh}_{3} \mathrm{O}^{-}$. The relative energies are given in $\mathrm{eV}$. The symmetry and electronic states are also shown. (b) Comparison between the experimental photoelectron spectrum and the simulated density of states (DOS) spectra for the low-lying energy isomers of $\mathrm{Rh}_{3} \mathrm{O}^{-}$with different electronic states. The DOS spectra were conducted by fitting the distribution of the transition lines with unit-area Gaussian functions of $0.20 \mathrm{eV}$ full width at half maximum (FWHM). 


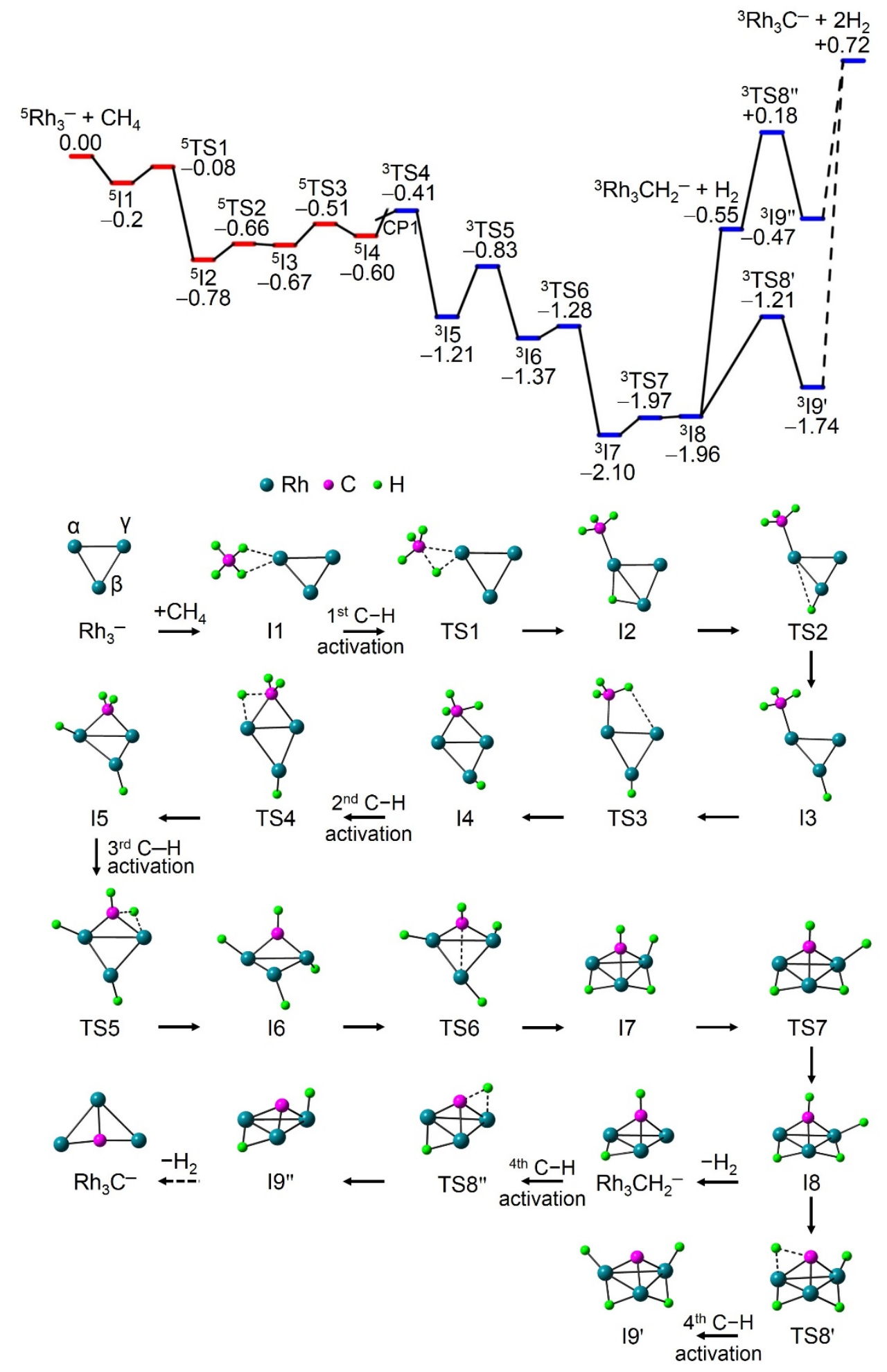

Figure S5. DFT calculated potential energy profile for the reaction of ${ }^{5} \mathrm{Rh}_{3}{ }^{-}+\mathrm{CH}_{4}(\mathrm{R} 1)$. The relative energies $\left(\Delta H_{0}, \mathrm{eV}\right)$ of reaction intermediates, transition states, and products with respect to the separated reactants are given. The superscript denotes the spin multiplicity.

DFT calculations about the path of ${ }^{3} \mathrm{Rh}_{3} \mathrm{CH}_{2}{ }^{-} \rightarrow{ }^{3} \mathrm{Rh}_{3} \mathrm{C}^{-}+\mathrm{H}_{2}$ demonstrate that an overall positive barrier $\left(+0.18 \mathrm{eV},{ }^{3} \mathrm{TS} 8\right.$ ") is encountered for activation of the $\mathrm{C}-\mathrm{H}$ bond in ${ }^{3} \mathrm{Rh}_{3} \mathrm{CH}_{2}{ }^{-}$. Note that the activation of the forth $\mathrm{C}-\mathrm{H}$ bond in $\mathrm{I} 8$ is kinetically favorable, however, the reaction of ${ }^{3} \mathrm{Rh}_{3}{ }^{-}+\mathrm{CH}_{4}$ $\rightarrow{ }^{3} \mathrm{Rh}_{3} \mathrm{C}^{-}+2 \mathrm{H}_{2}$ is endothermic by $0.72 \mathrm{eV}$, in consistent with the absence of product ion $\mathrm{Rh}_{3} \mathrm{C}^{-}$in experiments (Figure $1 \mathrm{~b}$ in main text). By contrast, the dissociative adsorption of an $\mathrm{O}_{2}$ molecule by $\mathrm{Rh}_{3} \mathrm{CH}_{2}{ }^{-}$ion significantly lowers the energy level of potential energy surfaces and renders desorption of the second $\mathrm{H}_{2}$ molecule (I18 $\rightarrow$ I19) thermodynamically and kinetically favorable (Figure S7). 


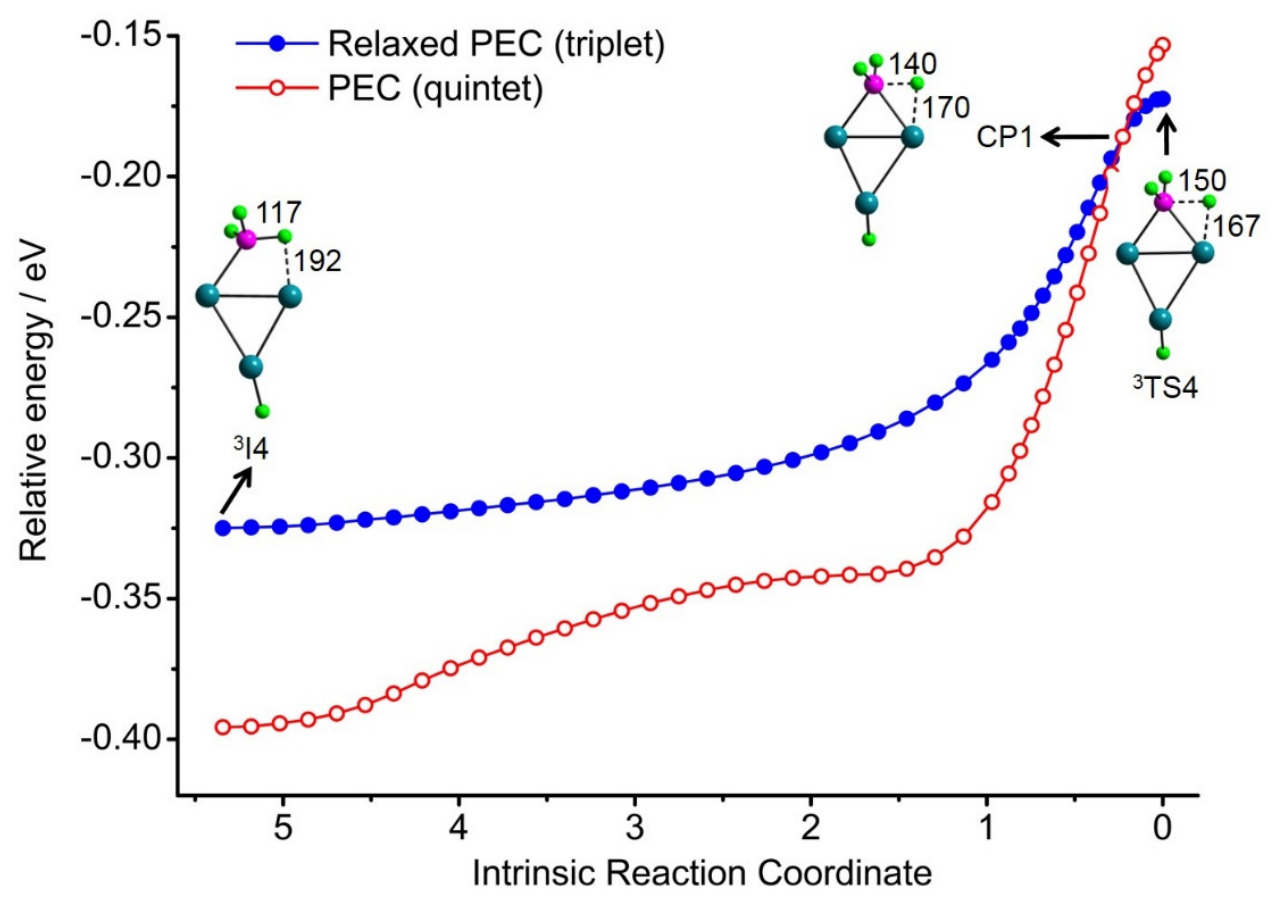

Figure S6. DFT calculated potential energy curves (PECs) for the interconversion of ${ }^{5} \mathrm{I} 4 \rightarrow{ }^{3} \mathrm{TS} 4$ in the reaction of ${ }^{5} \mathrm{Rh}_{3}{ }^{-}+\mathrm{CH}_{4}$ (Figure S5). The curve for the triplet state was obtained from the intrinsic reaction coordinate (IRC) calculation. The energies of the quintet states were calculated at the IRC determined geometries of triplet states. The relative energies with respect to the separated reactants $\left({ }^{5} \mathrm{Rh}_{3}{ }^{-}+\mathrm{CH}_{4}\right)$ are shown without zero-point vibration correction. The relative energy of the crossing point (CP1) with zero-point vibration correction is $-0.42 \mathrm{eV}$. 


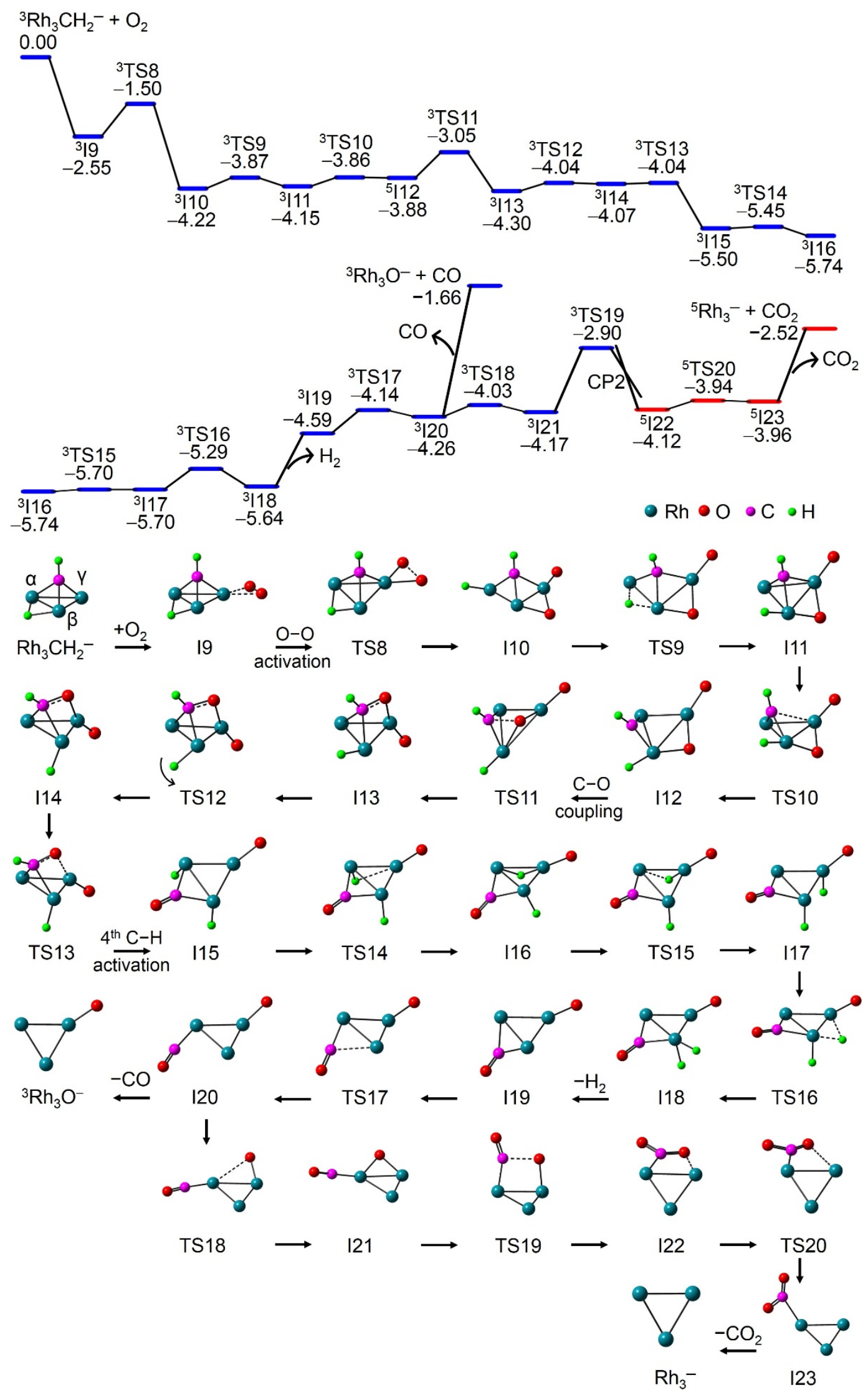

Figure S7. DFT calculated potential energy profile for the reaction of ${ }^{3} \mathrm{Rh}_{3} \mathrm{CH}_{2}{ }^{-}\left({ }^{3} \mathrm{IS} 3\right)$ with $\mathrm{O}_{2}$. The relative energies $\left(\Delta H_{0}, \mathrm{eV}\right)$ of reaction intermediates, transition states, and products with respect to the separated reactants $\left({ }^{3} \mathrm{Rh}_{3} \mathrm{CH}_{2}{ }^{-}+\mathrm{O}_{2}\right)$ are given. The superscript denotes the spin multiplicity. 


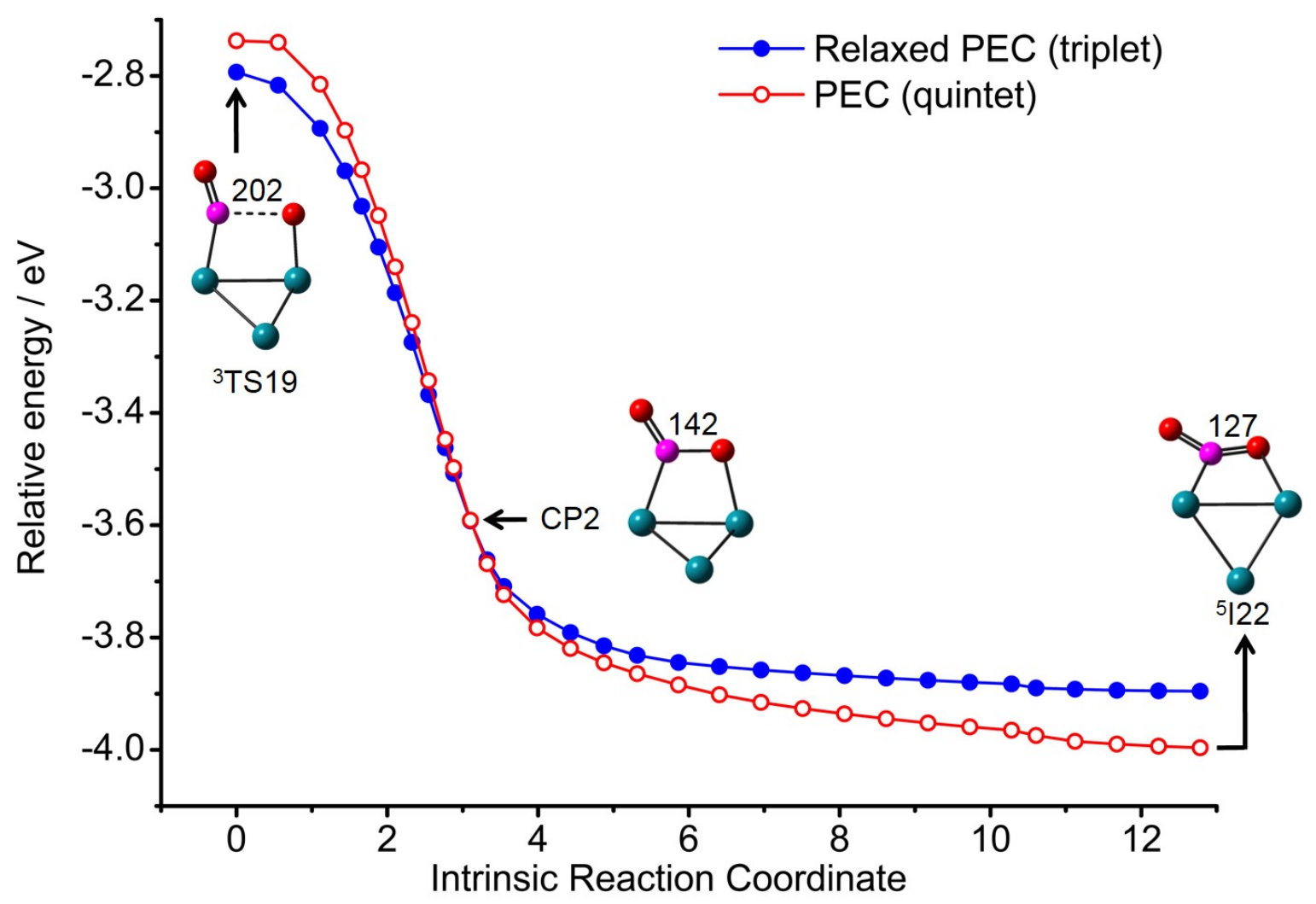

Figure S8. DFT calculated potential energy curves (PECs) for the interconversion of ${ }^{3} \mathrm{TS} 19 \rightarrow{ }^{5} \mathrm{I} 22$ in the reaction of ${ }^{3} \mathrm{Rh}_{3} \mathrm{CH}_{2}{ }^{-}+\mathrm{O}_{2} \rightarrow{ }^{5} \mathrm{Rh}_{3}{ }^{-}+\mathrm{H}_{2}+\mathrm{CO}_{2}$ (Figure S7). The curve for the triplet state was obtained from the intrinsic reaction coordinate (IRC) calculation. The energies of the quintet states were calculated at the IRC determined geometries of triplet states. The relative energies with respect to the separated reactants $\left({ }^{3} \mathrm{Rh}_{3} \mathrm{CH}_{2}{ }^{-}+\mathrm{O}_{2}\right)$ are shown without zero-point vibration correction. The relative energy of the crossing point $(\mathrm{CP} 2)$ with zero-point vibration correction is $-3.66 \mathrm{eV}$. 


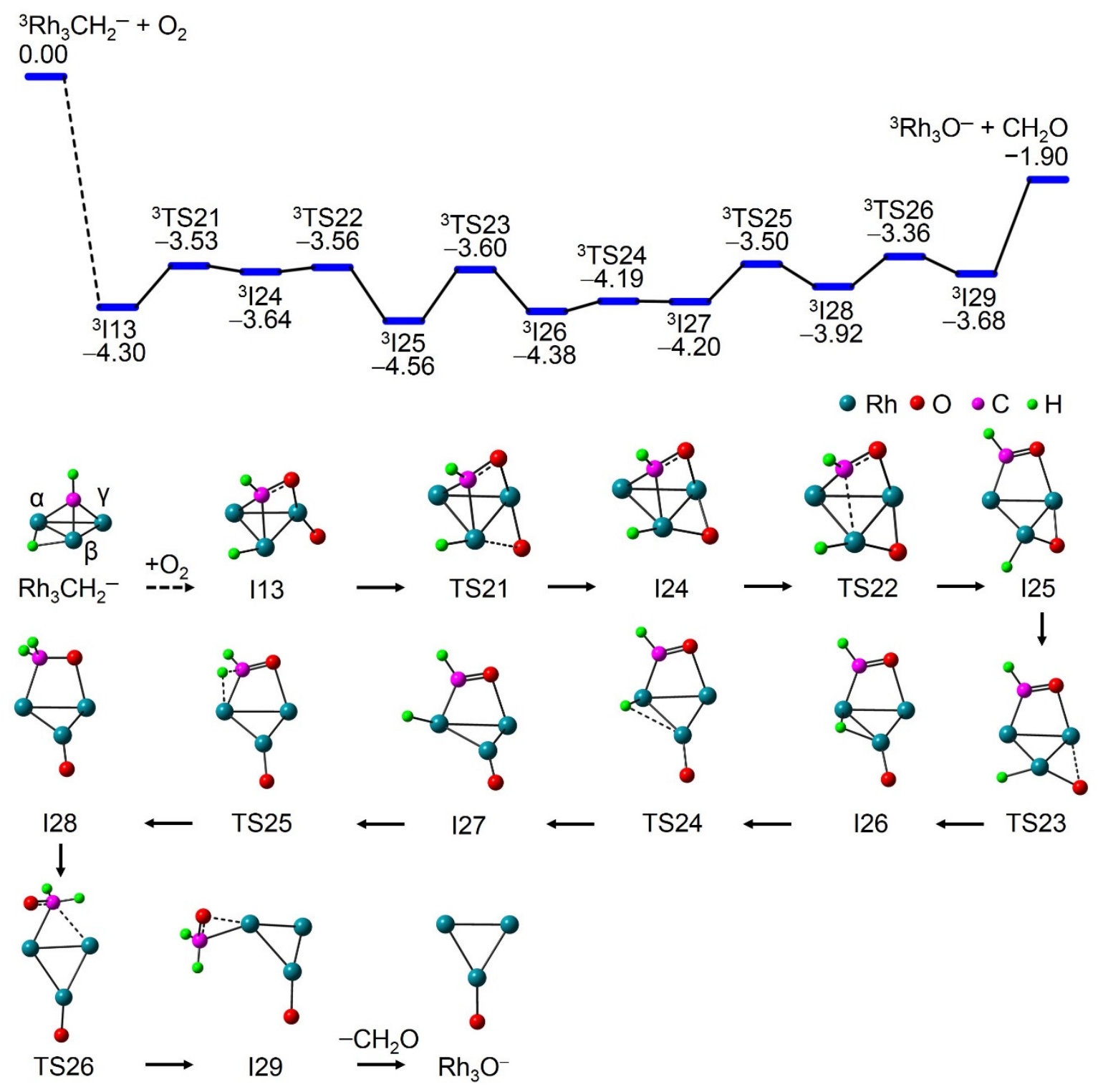

Figure S9. DFT calculated potential energy profile for the reaction of ${ }^{3} \mathrm{Rh}_{3} \mathrm{CH}_{2}{ }^{-}\left({ }^{3} \mathrm{IS} 3\right)+\mathrm{O}_{2} \rightarrow{ }^{3} \mathrm{Rh}_{3} \mathrm{O}^{-}$ $+\mathrm{CH}_{2} \mathrm{O}$. The relative energies $\left(\Delta H_{0}, \mathrm{eV}\right)$ of reaction intermediates, transition states, and products with respect to the separated reactants $\left({ }^{3} \mathrm{Rh}_{3} \mathrm{CH}_{2}{ }^{-}+\mathrm{O}_{2}\right)$ are given. The superscript denotes the spin multiplicity. 
Table S1. The virtual frequency values of all of the transition states shown in Figures 4 (main text), S5, S7, and S9.

\begin{tabular}{llll}
\hline TSs & Frequency $\left(\mathrm{cm}^{-1}\right)$ & TSs & Frequency $\left(\mathrm{cm}^{-1}\right)$ \\
\hline${ }^{5} \mathrm{TS} 1$ & -741.06 & ${ }^{3} \mathrm{TS} 13$ & -116.40 \\
${ }^{5} \mathrm{TS} 2$ & -82.37 & ${ }^{3} \mathrm{TS} 14$ & -325.10 \\
${ }^{5} \mathrm{TS} 3$ & -62.16 & ${ }^{3} \mathrm{TS} 15$ & -174.39 \\
${ }^{3} \mathrm{TS} 4$ & -762.54 & ${ }^{3} \mathrm{TS} 16$ & -577.41 \\
${ }^{3} \mathrm{TS} 5$ & -838.54 & ${ }^{3} \mathrm{TS} 17$ & -215.27 \\
${ }^{3} \mathrm{TS} 6$ & -226.54 & ${ }^{3} \mathrm{TS} 18$ & -89.26 \\
${ }^{3} \mathrm{TS} 7$ & -327.76 & ${ }^{3} \mathrm{TS} 19$ & -366.75 \\
${ }^{3} \mathrm{TS} 81$ & -781.49 & ${ }^{5} \mathrm{TS} 20$ & -20.86 \\
${ }^{3} \mathrm{TS} 8 "$ & -793.88 & ${ }^{3} \mathrm{TS} 21$ & -163.22 \\
${ }^{3} \mathrm{TS} 8$ & -432.77 & ${ }^{3} \mathrm{TS} 22$ & -166.76 \\
${ }^{3} \mathrm{TS} 9$ & -148.31 & ${ }^{3} \mathrm{TS} 23$ & -184.18 \\
${ }^{3} \mathrm{TS} 10$ & -131.31 & ${ }^{3} \mathrm{TS} 24$ & -283.03 \\
${ }^{3} \mathrm{TS} 11$ & -402.65 & ${ }^{3} \mathrm{TS} 25$ & -764.14 \\
${ }^{3} \mathrm{TS} 12$ & -188.29 & ${ }^{3} 26$ & -105.59 \\
\hline
\end{tabular}




\section{References}

[1] Z. Yuan, Y.-X. Zhao, X.-N. Li, S.-G. He, Int. J. Mass Spectrom. 2013, 354-355, 105-112.

[2] Z. Yuan, Z.-Y. Li; Z.-X.Zhou, Q.-Y. Liu, Y.-X. Zhao, S.-G. He, J. Phys. Chem. C 2014, 118, 14967 $-14976$.

[3] X.-N. Wu, B. Xu, J.-H. Meng, S.-G. He, Int. J. Mass Spectrom. 2012, 310, 57-64.

[4] Q.-Y. Liu, L. Hu, Z.-Y. Li, C.-G. Ning, J.-B. Ma, H. Chen, S.-G. He, J. Chem. Phys. 2015, 164301.

[5] M. J. Frisch, G. W. Trucks, H. B. Schlegel, G. E. Scuseria, M. A. Robb, J. R. Cheeseman, G.Scalmani, V. Barone, B. Mennucci, G. A. Petersson, H. Nakatsuji, M. Caricato, X. Li, H. P. Hratchian, A. F. Izmaylov, J. Bloino, G. Zheng, J. L. Sonnenberg, M. Hada, M. Ehara, K. Toyota, R. Fukuda, J. Hasegawa, M. Ishida, T. Nakajima, Y. Honda, O. Kitao, H. Nakai, T. Vreven, J. J. A. Montgomery, J. E. Peralta, F. Ogliaro, M. Bearpark, J. J. Heyd, E. Brothers, K. N. Kudin, V. N. Staroverov, R. Kobayashi, J. Normand, K. Raghavachari, A. Rendell, J. C. Burant, S. S. Iyengar, J. Tomasi, M. Cossi, N. Rega, J. M. Millam, M. Klene, J. E. Knox, J. B. Cross, V. Bakken, C. Adamo, J. Jaramillo, R. Gomperts, R. E. Stratmann, O. Yazyev, A. J. Austin, R. Cammi, C. Pomelli, J. W. Ochterski, R. L. Martin, K. Morokuma, V. G. Zakrzewski, G. A. Voth, P. Salvador, J. J. Dannenberg, S. Dapprich, A. D. Daniels, O. Farkas, J. B. Foresman, J. V. Ortiz, J. Cioslowski, a. D. J. Fox, Gaussian 09, Revision A.01; Gaussian, Inc., Wallingford, CT, 2009.

[6] J. P. Perdew, K. Burke, M. Ernzerhof, Phys. Rev. Lett. 1996, 77, 3865-3868.

[7] Y. Ren, Y. Yang, Y.-X. Zhao, S.-G. He, J. Phys. Chem. C 2019, 123, 17035-17042.

[8] A. Schäfer, C. Huber, R.Ahlrichs, J. Chem. Phys. 1994, 100, 5829-5835.

[9] M. Dolg, H. Stoll, H. Preuss, J. Chem. Phys. 1989, 90, 1730-1734.

[10] I. Berente, G. Náray-Szabó, J. Phys. Chem. A 2006, 110, 772-778.

[11] J. I. Steinfeld, J. S. Francisco, W. L. Hase, Chemical Kinetics and Dynamics, Upper Saddle River, New Jersey, Prentice-Hall, 1999.

[12] T. Beyer, D. R. Swinehart, Commun. ACM 1973, 16, 379. 